\title{
ZONA DE CISALHAMENTO TRANSCORRENTE DORSAL DE CANGUÇU: CARACTERIZAÇÃO E IMPORTÂNCIA NA COMPARTIMENTAÇÃO TECTÔNICA DO CINTURÃO DOM FELICIANO*
}

\author{
LUÍS A.D. FERNANDES ${ }^{* * *}$, ANDRÉA TOMMASI***, ALAIN VAUCHEZ***, \\ CARLA C. PORCHER**, RUALDO MENEGAT**, EDINEI KOESTER**
}

\begin{abstract}
THE DORSAL DE CANGUÇU STRIKE-SLIP SHEAR ZONE OF THE UPPER PROTEROZOIC DOM FELICIANO BELT OF SOUTHERN BRAZIL: MAIN CHARACTERISTICS AND TECTONICIMPORTANCE. Crustal-scale strike-slip shear zones of the inner part of Dom Feliciano Belt show evidence of a long history of left-lateral movement. They started as transtensional structures along which porphyritic granitoids with mantle-derived signature and a well-developed magmatic fabric were emplaced, followed by the intrusion of a suite of crustal-derived peraluminous leucogranites. Several stages of movement of these shear zones where recognized and characterized at different scales. The eldest is typified by a welldeveloped magmatic planar and linear fabric with NE-NS trends in syntectonic granites. Transitional magmatic to solid state deformational microstructures include undeformed quartz grains within feldspars showing high temperature deformation. Abundant myrmekites along. contacts between feldspar porphyroclasts and matrix are suggestive of stress induced diffusion. Mechanical twining, kink bands and interpenetrating grain boundaries in plagioclase crystals indicates that oriented growth was active. Other high-T structures include grain boundary migration in quartz and grain-size comminution of K-feldspars through ubiquitous development of myrmekites producing a granoblastic polygonal texture. Quartz occurs as mono or polycrystalline ribbons with large polygonal grains with lobate boundaries while biotite shows grain-size reduction keeping cleavage planes parallel to the main foliation. Lovv-T microstructures are abundant in thick sequences of phyllonites and quartz mylonites and nucleation of new grains was the main grain-size reduction process during this stage. Extensive fracturing of feldspar crystals and their replacement by white mica and biotite suggests abundance of fluids. Quartz shows basal slip during this stage. Mylonites of these $10 \mathrm{~s}$ of $\mathrm{km}$-thick shear zones are affected by several sets of syngenetic and late folds The former show variable geometry becoming cylindrical towards the high strain zones. These strike-slip shear zones which were formerly interpreted as boundaries between allochthonous terranes and collisional sutures are better interpreted as intracontinental structures responsible for the accomodation of late-orogenic belt-parallel movement.
\end{abstract}

Keywords: PanAfrican, Precambrian shield, shear zone, strike-slip tectonics.

RESUMO As zonas de cisalhamento transcorrente de escala crustal, das porções internas do Cinturão Dom Feliciano, mostram evidências de uma longa história de movimento sinistrai. Iniciaram-se como estruturas transtrativas ao longo das quais posicionaram-se granitóides porfiríticos com assinatura mantélica e trama magmática bem desenvolvida, seguidos pela intrusão de uma suíte de leucogranitos peraluminosos. Diversos estágios de movimentacão dessas zonas de cisalhamento foram reconhecidos e caracterizados em diferentes escalas. O mais antigo é caracterizado por uma foliação e lineação de fluxo magmático com trends NE-NS, em granitóides sintectônicos. Microestruturas do estágio de deformação transicional (magmático - estado sólido) incluem grãos de quartzo não-deformados no interior de feldspatos com feições de deformação de alta temperatura. O estágio de deformação de alta temperatura no estado sólido é caracterizado, na escala microscópica, por abundantes mirmequitas ao longo de contatos entre os porfiroclastos de feldspatos; a matriz sugere a ocorrência de difusão induzida por tensão (stress induced diffusion). Macias mecânicas, kink bands e limites de grãos interpenetrados em cristais de plagioclásio sugerem a ocorrência de crescimento orientado. Outras estruturas de alta temperatura incluem migração de limites de grãos em quartzo e redução de tamanho de grão de feldspatos pelo desenvolvimento de mirmequitas culminando com o desenvolvimento de textura granoblástica poligonal. O quartzo ocorre como fitas mono ou policristalinas, com grandes grãos poligonais de limites lobados, enquanto a biotita mostra redução de tamanho de grão, mantendo, no entanto, os planos de clivagem paralelos à foliação principal. Microestruturas de baixa temperatura são abundantes em espessas sequências de filonitos e quartzo milonitos e a nucleação de novos grãos foi o principal processo de redução de tamanho de grão durante esse estágio de deformação. Fraturamento extensivo de cristais de feldspato, bem como a sua substituição por mica branca e biotita, sugere abundância de fluidos durante a deformação. O quartzo mostra deslizamento basal durante esse estágio. Os milonitos dessas zonas de cisalhamento, com dezenas de quilómetros de espessura, foram afetados por diversas gerações de dobras singenéticas e tardias. As primeiras mostram geometrias variáveis, tornando-se cilíndricas em direção às zonas de alta deformação. Essas zonas de transcorrência, originalmente interpretadas como limites entre terrenos alóctones e suturas colisionais, são mais apropriadamente interpretadas como estruturas intracontinentais, responsáveis pela acomodação de movimento tectônico tardi-orogênico paralelamente ao alongamento do Cinturão Dom Feliciano.

Palavras-chave: Brasiliano, Pré-Cambriano, Escudo Sul-Rio-Grandense.

INTRODUÇÃO As zonas de cisalhamento transcorrentes das porções internas do Cinturão Dom Feliciano (Fig. 1), denominadas de "Cinturão Granítico Central e Falhas
Transcorrentes", no território do Uruguai, correspondem, no Escudo Sul-Rio-Grandense, ao originalmente denominado de "Sistema de Falhas Dorsal de Canguçu". Esse sistema foi

\footnotetext{
* Contribuição ao Projeto "O Comportamento Mecânico da Litosfera nos Cinturões de Colisão em Transpressão" (CNPq-CNRS)

** CPGq, Instituto de Geociências, Universidade Federal do Rio Grande do Sul, Caixa Postal 15065, CEP 91501-970, Poá, RS, Brasil, Email:FERNA@IFI.IF.UFRGS.BR

*** Laboratoire de Tectonophysique/USTL, 34095 Montpellier Cedex 5, França
} 
caracterizado por Picada (1971, p. 183) como sendo uma "zona de falhas profundas ('fratura abissal') de direção $\mathrm{N} 35 \mathrm{E}$ a N75E [...] com cerca de $10 \mathrm{~km}$ de largura e $150 \mathrm{~km}$ de extensão $[. .$.$] ao longo da qual se alinham corpos de$ granitos e migmatitos recortados por brechas de milonitos e cataclasitos de grandes dimensões". A origem e papel tectônico desempenhado na evolução da deformação durante o Ciclo Brasiliano, pela atualmente conhecida como "Zona de Cisalhamento Dorsal de Canguçu" (Fernandes et al. 1990, Mesquita \& Fernandes 1990), são ainda bastante discutidos. Essa zona de alta deformação foi interpretada como (i) uma sutura entre duas placas litosféricas (Issler 1982, Figueiredo et al. 1990, Fragoso-César et al. 1990) e (ii) uma zona de cisalhamento intraplaca relacionada a uma colisão oblíqua durante o Ciclo Brasiliano (Fragoso-César et al 1986).

Até recentemente, os únicos dados disponíveis sobre as características das estruturas agrupadas nesse 'sistema' eram advindos de mapeamentos da década de 60 ( $c f$. Picada 1971 e referências). As poucas publicações das duas últimas décadas sobre o assunto (Ribeiro 1980, Jost et al. 1984) foram tentativas de sistematização de escopo geral, baseadas na utilização de critérios singulares e muitas vezes não-apropriados, como, por exemplo, o uso do trena dessas estruturas. Dessa forma, inviabilizaram a adoção das propostas de classificação até então apresentadas, que incluíam as zonas de cisalhamento de direção geral NE no Sistema Dorsal de
Canguçu, entre outras. Os maiores problemas das referidas proposições parecem decorrer, no entanto, do agrupamento genético de rochas e feições estruturais de idades diversas e produzidas por fluxo plástico (comportamento dúctil) e cataclástico (comportamento rúptil), ao longo dessas zonas de alta deformação (e.g. Tessari \& Picada 1966, Picada 1971, Fragoso-César et al. 1986).

Todavia, os estudos sobre os sistemas de falhas no Escudo Sul-Rio-Grandense possuem estatuto epistêmico de terem se constituído no elemento motor da mutação dos modelos geológicos em cada período da história da pesquisa dessa área desde a década de 30 ( $c f$. Menegat 1992). A identificação dos significados distintos que os grandes lineamentos reconhecidos nesse escudo possuíram na explicação geológica acaba por identificar também os diferentes períodos da própria história da pesquisa geológica e das diferentes abordagens epistêmicas existentes em cada um deles. Desse modo, as distintas compreensões que foram sendo construídas sobre os lineamentos ao longo do desenvolvimento das pesquisas, ao mesmo tempo que possibilitavam o falseamento ( $c f$. Popper 1980) de modelos anteriores, eram elementos fundamentais na proposição dos novos modelos. Não há nenhum exagero de afirmar-se, portanto, que o correio entendimento da importância do 'Sistema Dorsal de Canguçu' na estruturação do Cinturão Dom Feliciano é condição sine qua non para testar a consistência dos modelos tectônicos propostos para o mesmo. Apesar disso, ne-

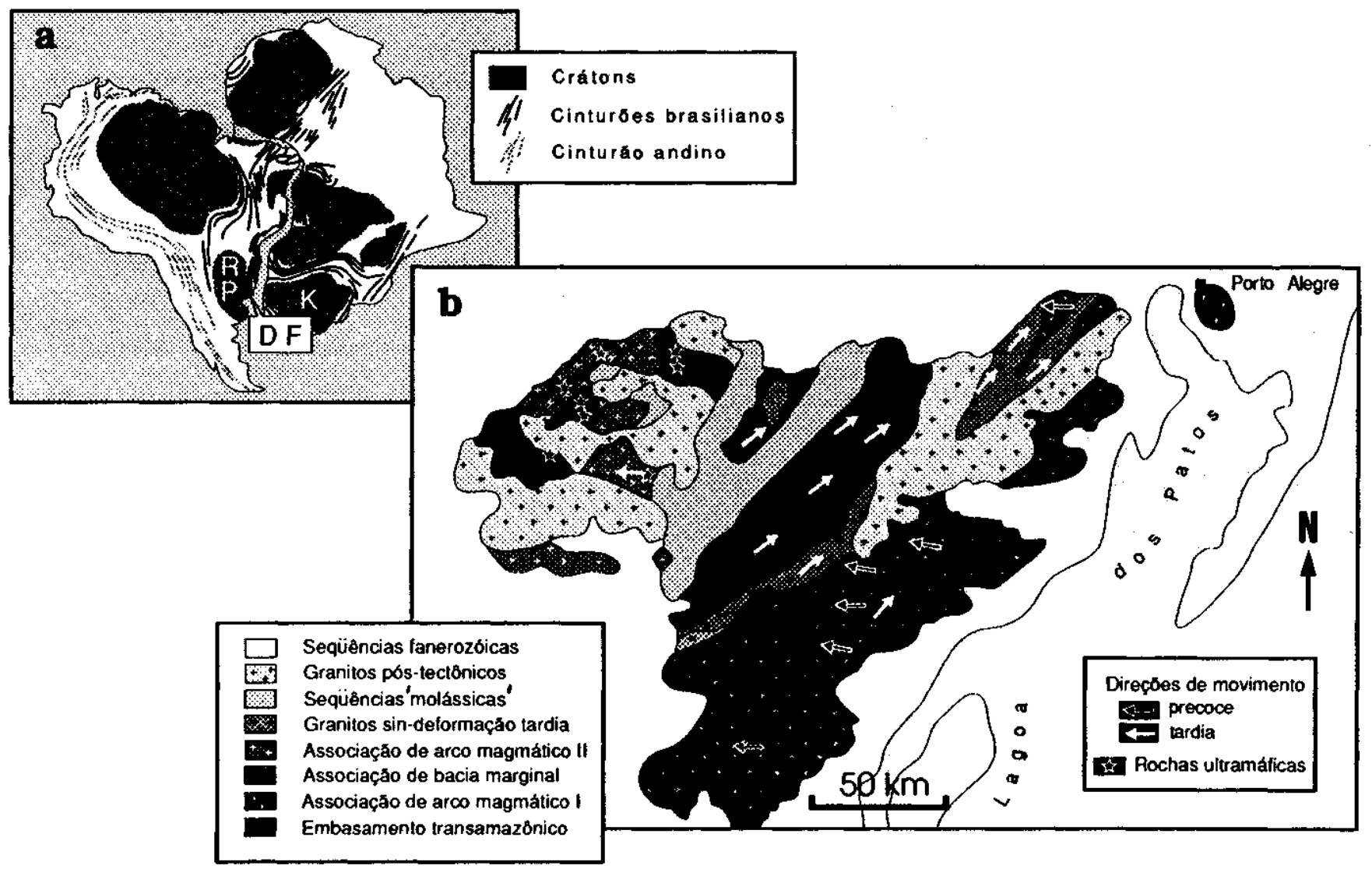

Figura 1-a. Posição do Cinturão Dom Feliciano (DF) em relação aos Crátons do Rio de Ia Plata (RP), Kalahari (K) e demais unidades geotectônicas do sistema geodinâmico Brasiliano/Pan-africano. b. Principais associaçôes petrotectônicas do DF, segundo Tommasi \& Fernandes (1990). Neste mapa, os granitóides sintectônicos à Zona de Cisalhamento Transcorrente Dorsal de Canguçu são denominados de "Granitos sin-deformação Tardia" e as zonas tangenciais, com movimento do topo para NE, correspondem à "Associação de bacia marginal" (Extraído de Tommasi et al. 1992b, Fig. 1)

Figure 1 - a. Position of Dom Feliciano Belt (DF) in relation to Rio de Ia Plata (RP) and Kalahari (K) cratons and other geotectonic units of the Panafrican Brasiliano geodynamic system. b. Main petrotectonic assemblages of DF according to Tommasi \& Fernandes (1990). In this map the syntectonic granitoids of Dorsal de Canguçu Shear Zone are named "Granitos sin-deformação Tardia" and the flat-lying shear zones with a top-to-NE sense of movement correspond to "Associação de bacia marginal" (Reproduced from Tommasi et al. 1992b, Fig. 1) 
nhuma revisão pormenorizada foi ainda dedicada a esse importante assunto, nesta década.

Com efeito, durante longo período de desenvolvimento das pesquisas, que se estende de 1823 até o final da década de 1950, falhas não foram reconhecidas no Escudo Sul-Riograndense. As primeiras estruturas desse tipo foram reportadas por Melcher \& Mau (1960), na região de Caçapava do Sul. Antes dessa data, tais feições foram definidas, na década de 30, como 'simples fraturas' (Carvalho 1932, Teixeira 1937), e na década subsequente como 'zonas perturbadas' (Leinz \& Barbosa 1941), em que, pela primeira vez, colocou-se a possibilidade de existência de relação genética entre 'sistemas de fraturas' e magmatismo. Mas foi na década de 60 que a escala regional desses lineamentos foi identificada, sendo os mesmos denominados de 'grandes zonas de falhas' (Picada 1971). Os conceitos que presidiram esses estudos foram, sob o ponto de vista téctônico, aqueles enunciados por Beloussov (1962, deep fractures) e, sob o ponto de vista da complexidade litológica associada a essas estruturas, aqueles enunciados pela teoria metassomatista. Todas essas abordagens pressupunham uma natureza eminentemente rúptil para as zonas de falhas, funcionando as mesmas como condutos para a ascensão de magmas, fluidos e 'frentes metassomáticas'. A natureza dúctil de algumas dessas estruturas somente veio a ser reconhecida na década de 80 (Jost 1981), quando rochas até então interpretadas como 'xistos' da Formação Vacacaí (e.g. Carraro et al, 1974) foram identificadas como milonitos e filonitos.

Questionando a sistematização proposta por Picada (1971), os trabalhos de Jost (1981), Frantz \& Jost (1983) e Jost et al. (1984, p. 1713) lideraram a busca de critérios mais adequados para caracterizar os sistemas de falhas reconhecidos no Escudo Sul-riograndense. Esses autores, embora apresentem um resumo das feições utilizadas na classificação então proposta (Tab. I, Jost et al. 1984), não forneceram critérios atualmente considerados como essenciais para a sua sistematização genética, ou seja, descrições das rochas formadas durante as diferentes condições 'ambientais' (P-T) e das microestruturas observadas nas unidades litoestruturais afetadas (protólitos dos milonitos), bem como as características do magmatismo sintectônico associado. No entanto, mesmo nessa época, sugestões acerca da contemporaneidade entre zonas de alta deformação com características metamórficas marcadamente diferentes foram igualmente inconsistentes. Exemplo disso, foi a interpretação dos Sistemas Vigia-Roque (deformação dúctil, direção NE e sinistrai) e Passo do Marinheiro (deformação rúptil predominante, direção N-S e dextral) como um par conjugado, baseada somente na compatibilidade do sentido de movimentação.

$\mathrm{O}$ estudo das estruturas tradicionalmente inclúídas na Zona de Cisalhamento Dorsal de Canguçu foi retomado por Fernandes et al (1990) e Tommasi et al. (1992a, 1994) na região de Encruzilhada do Sul e Piratini, onde, com base em princípios da moderna análise estrutural, foi reconhecida a existência de duas zonas de alta deformação de natureza e idades claramente diversas. Essas zonas, em virtude de suas orientações, poderiam, de acordo com os critérios utilizados na literatura regional (e.g. Picada 1971, Jost et al. 1984), ser classificadas como parte do mesmo sistema. No entanto, foi preliminarmente demonstrado, que as zonas de alta deformação mais antigas e de mais alta temperatura são de natureza tangencial, e, como essas afetam exclusivamente os grantóides cordilheiranos da Associação de Arco Magmático I e suas encaixantes (cf. Fernandes et al. 1992b), sendo truncadas pelas Zonas de Cisalhamento Transcorrente Dorsal de Canguçu (ZCTDC) e granitóides sintectônicos associados, não fazem parte do 'Sistema Dorsal de Canguçu'.

Assim, após uma breve (i) revisão dos critérios atualmente utilizados na análise estrutural para a sistematização de zonas de Cisalhamento e sua comparação com a literatura regional e (ii) caracterização das principais feições associadas aos diferentes estágios de movimentação da ZCTDC, passa-se a discutir alguns aspectos da natureza e papel téctônico desempenhado por essas estruturas na evoluçãa do Cinturão Dom Feliciano durante o Proterozóico Superior.

ANÁLISE ESTRUTURAL Qualquer metodologia uti^ lizada na análise estrutural de cinturões orogênicos deve considerar que o desenvolvimento de zonas de Cisalhamento é a expressão, por excelência, da deformação da crosta continental por causa do comportamento elasto-plástico que esta apresenta (cf. Taponnier \& Moinar 1976). A deformação (heterogénea) foi, assim, acomodada principalmente pelo deslocamento de 'blocos' ao longo de zonas de alta deformação, geralmente de escala continental, cuja disposição, orientação e cinemática em um determinado cinturão, estão relacionadas à dinâmica das placas responsáveis pela sua génese. A cinemática de convergência, geometria dos limites e existência de heterogeneidades herdadas ou adquiridas pela crosta continental, entre outros fatores, condiciona a nucleação e o desenvolvimento das zonas de alta deformação, de modo que a evolução tectônica dos cinturões orogênicos pode ser desvendada pela integração das características cinemáticas das suas principais zonas de Cisalhamento (Vauchez 1987).

Para o reconhecimento de quais zonas de Cisalhamento foram parte do mesmo sistema mecânico, faz-se necessária a determinação de suas idades, visto que muitas dessas estruturas, embora mostrando padrões cinemáticos similares, podem apresentar idades diversas, enquanto outras zonas de alta deformação, apresentando padrões cinemáticos diferentes, podem ser contemporâneas (Fernandes et al. 1991). Assim, pelo diacronismo da deformação, durante a evolução tectônica do orógeno, e pela dificuldade de datação direta das zonas de Cisalhamento, o que dependeria da utilização de métodos radiométricos sofisticados (e.g. Ar-Ar), qualquer tentativa de desvendar as relações genéticas entre zonas de alta deformação de um determinado cinturão passa necessariamente pelo estabelecimento de suas características metamórfico-deformacionais e magmáticas vista a restrita possibilidade de que zonas de alta deformação que apresentem características idênticas não sejam cogenéticas.

Como a deformação pode ser traduzida em termos de fluxo de rocha no estado sólido, materializado por elementos estruturais mesoscópicos e microscópicos dos tectonitos (Nicolas \& Poirier 1976), o objetivo principal do estudo da deformação em zonas de Cisalhamento é a determinação, em diversas escalas, das características e geometria do fluxo téctônico, incluindo a geometria da zona de Cisalhamento, a orientação do plano (superfície) de fluxo e a direção e sentido do mesmo.

A história térmica do fluxo téctônico (metamorfismo sintectônico) pode ser determinada por um exame, na escala microscópica, dos mecanismos de deformação mineral responsáveis pelo mesmo, que se utiliza de conceitos de metalurgia física. Assim, microestruturas típicas de cada mecanismo de deformação em diferentes minerais podem ser reconhecidas por meio da comparação entre rochas afetadas por deformação natural e experimental, permitindo uma avaliação das condições que controlam a ativação de cada mecanismo de deformação (cf. Schmid 1982, Kirby 1985, Paterson 1987, Knipe 1989, Rutter \& Brodie 1991). Atualmente, está bem estabelecido que a ativação de um mecanismo de deformação específico em determinada espécie mineral é controlada principalmente pela temperatura, tensão diferencial, taxa de deformação, pressão de fluidos e tamanho de grão. No caso da deformação de agregados poliminerálicos, o comportamento reológico é definido pelo 'mineral-guia', que, além de constituir-se em fase mineral abundante, deve acomodar a deformação nas condições físicas 
vigentes, pela atuação de um mecanismo de deformação mais eficaz que os dos demais minerais que ocorrem em proporções equivalentes na rocha (Vauchez 1987, Tommasi 1991, Porcher 1992).

Dados como esses são necessários para uma avaliação, mesmo que preliminar, das condições de P-T e de deformação das rochas afetadas. Quando a esses integram-se as características cinemáticas e magmáticas geradas durante as diversas fases de movimentação das zonas de cisalhamento, em geral, e as do 'Sistema Dorsal de Canguçu', em particular, pode-se fornecer subsídios para a análise do sistema mecânico responsável pela génese dessas estruturas, permitindo a elaboração de propostas de sistematização das mesmas baseadas em critérios mais adequados.

De outra parte, as características do magmatismo sincinemático permitem avaliar a natureza e as relações genéticas entre as diversas zonas de cisalhamento, pela determinação das idades relativas entre eventos metamórficodeformacionais e episódios magmáticos, bem como a obtenção das idades radiométricas e características petrológicas das intrusões sincinemáticas (fusão de crosta/manto etc.). Assim, a natureza litosférica (ou 'apenas' crustal) de um conjunto de zonas de cisalhamento pode ser determinada por estudos petrológicos do magmatismo associado, permitindo (i) avaliação de suas possíveis fontes e, conseqüentemente, (ii) distinção entre zonas de alta deformação cogenéticas (as que apresentam o mesmo tipo de magmatismo), separandose as estruturas precoces das feições produzidas por reativações (cf. Tommasi et al. 1992a, 1994).

No caso da ZCTDC, tanto as características das microestruturas desenvolvidas, quanto a presença de granitóides sintectônicos à fase de movimentação precoce dessas zonas de alta deformação permitiram o reconhecimento de diversos episódios de reativação dessas estruturas, bem como a fatorização qualitativa preliminar da deformação acomodada ao longo das mesmas. Assim, embora feições associadas às zonas de cisalhamento do Sistema Dorsal de Canguçu tenham sido objeto de publicações anteriores (cf. Fernandes et al 1988, 1990, 1992a e Tommasi et al 1992a, 1994), algumas das suas principais características serão resgatadas no item a seguir, com o objetivo de distinguir-se entre as diversas fases de movimentação, além de discutir a sua influência na estruturação tectônica do Cinturão Dom Feliciano.

Caracterização das Zonas de Cisalhamento Transcorrentes Dorsal de Cangucu A fase de movimentação precoce da ZCTDC é registrada por zonas de cisalhamento transcorrente de escala litosférica, que acomodaram a principal movimentação tectônica longitudinal do cinturão. Tais zonas são reconhecidas principalmente a partir das ocorrências, características petrológicas e estruturais de granitóides porfiríticos e peraluminosos sintectônicos. O estudo da distribuição, geometria, metamorfismo e outras características dessas estruturas originadas durante a referida fase de movimentação torna-se dificultado, tanto pela obliteração dos registros dessa deformação em unidades litoestratigráficas mais antigas (e.g. 'granitóides cordilheiranos', cf. Fernandes et al. 1992b) por deformação de baixa temperatura e abundância de fluidos, originando filonitos, quanto pela intrusão de grande volume de granitóides mais novos e recobrimento por rochas sedimentares. A raridade de registros dessa fase da deformação levou Tommasi et al. (1992a,1993) a deduzirem que grande parte da movimentação longitudinal, principalmente na porção NE da ZCTDC, pode ter sido acomodada por fluxo no estado subsólido nos granitóides sintectônicos. A fase de movimentação precoce estaria, assim, registrada pela trama magmática dos granitóides.
A trama magmática dos granitóides porfiríticos sintranscorrência é materializada por conspícua foliação subvertical e lineacão suborizontal, definidas pela orientação dimensional de megacristais de feldspato potássico. Nos granitóides sintectônicos peraluminosos, o reconhecimento das feições magmáticas torna-se dificultado pelas suas características composicionais e texturais. No caso da ZCTCD, a ocorrência de dois granitóides peraluminosos (mapeáveis na escala de 1:25.000) foi reconhecida devido ao mapeamento sistemático desenvolvido na região de Encruzilhada do Sul (UFRGS 1988, 1992, 1993). Esses granitos apresentam idades diferentes, como evidenciado pelas relações de intrusão, sendo cortados por pegmatitos e graisens mostrando deformação limitada às zonas de contato. O Metagranito Arroio Francisquinho, descrito por Fernandes et al. $(1988,1990)$, é o mais antigo e mais penetrativamente deformado, sendo cortado por apófises de um leucogranito peraluminoso grosso, apresentando milonitização de baixa temperatura, localizada principalmente nos seus bordos. Esse último, aflora principalmente na porção SW da zona de cisalhamento, tendo sido denominado por Tessari \& Picada (1966) de Granito Cordilheira. Ambos foram definidos como sintectônicos às zonas de transcorrência, tendo sido incluídos na Suíte Granítica Cordilheira de Fragoso-César et al. (1986), constituindo-se em objeto de estudos petrológicos e geocronológicos em desenvolvimento (Koester 1995).

As estruturas do fluxo magmático são parte essencial na elucidação das características da movimentação precoce dessas zonas de cisalhamento transcorrente, fornecendo os poucos elementos disponíveis para a determinação da sua história evolutiva durante esse estágio. Desta forma, o sentido dextrógiro para o fluxo magmático é indicado pelo entelhamento de megacristais de feldspato potássico, como observado na porção SE dos granitóides porfiríticos, ao longo dos contatos com os granitóides cordilheiranos (Fernandes et al. 1992b). A confirmação desse padrão e a possibilidade de que o sentido de fluxo magmático seja oposto (levógiro) ao longo dos contatos NW dos granitóides porfiríticos, hipótese atualmente em investigação, podem sugerir que o magma tenha sido intrudido de SW para NE, além de servirem para a interpretação da natureza transtrativa ou transpressiva da zona de cisalhamento durante esse estágio de movimentação.

Os monzogranitos com granodioritos porfiríticos sintectônicos à ZCTDC são cálcico-alcalinos, metaluminosos a fracamente peraluminosos (termos mais diferenciados). Apresentam características de granitóides IMC (cf. Argue \& Brimhall 1988, p. 913), sugestivas de origem mantélica com certo grau de contaminação crustal, o que parece ser confirmado por sua posição no diagrama $\mathrm{Rb} \times \mathrm{Sr}$, proposto por esses autores, e pelas razões iniciais $\mathrm{Rb} / \mathrm{Sr}$ (em torno de 0,716 ), obtidas a partir de uma isócrona preliminar (Tommasi 1991). Já, os leucogranitos peraluminosos da Suíte Cordilheira, intrusivos nos granitóides porfiríticos, apresentam altas razões iniciais $\left(\mathrm{R}_{\varnothing}=0,732\right) \mathrm{e}$, sendo plotados no campo dos granitóides ISC do diagrama $\mathrm{Rb} \times \mathrm{Sr}$, caracterizam-se como granitóides de fusão crustal, embora não apresentem as características típicas de granitos do 'tipo $\mathrm{S}^{\prime}$ (cf. Fernandes et al. 1992b).

A discussão das consequências reológicas do magmatismo sintranscorrência na acomodação da deformacão em escala continental, bem como a descrição mais detalhada de suas principais características petrológicas e microestruturais são apresentadas por Tommasi et al. (1992a, 1994).

O estágio de deformação transicional entre o fluxo magmático e o tectônico é registrado em porções de baixa deformação dos granitos pela coexistência de microestruturas indicativas de deformação de alta temperatura em feldspatos contendo fraturas preenchidas por quartzo 
indeformado. O conspícuo desenvolvimento de mirmequitas ao longo dos contatos entre porfiroclastos desse mineral com a matriz de alta deformação sugerem que o processo de substituição é induzido por stress. Os plagioclásios mostram macias mecânicas, kinks, fraturas en échellon preenchidas por quartzo e contatos de grãos interpenetrados, sugerindo a ocorrência de crescimento orientado (Tommasi et al 1994).

A deformação de alta temperatura no estado sólido foi registrada localizadamente nos limites externos da zona de cisalhamento por blastomilonitos com foliação bem desenvolvida em virtude do tamanho avantajado das lamelas de micas e granadas. Dentre os protólitos dessas rochas, onde foi possível a sua identificação, destacam-se granitóides peraluminosos que ocorrem como pequenas lentes (dm a m), remanescentes da intensa deformação e metamorfismo. Segundo Tommasi et al. (1994), as principais microestruturas desenvolvidas nos granitóides sintranscorrência durante esse estágio de deformação incluem migração generalizada dos limites de grão dos cristais de quartzo e a instabilização do feldspato potássico, sugerindo a ocorrência de difusão. $\mathrm{O}$ desenvolvimento de mirmequitos é ainda bastante significativo, produzindo matriz de quartzo e feldspato com textura granoblástica, a partir do feldspato original. $\mathrm{O}$ quartzo ocorre como fitas mono ou policristalinas, com grãos poligonais avantajados e contatos interpenetrados, enquanto o plagipclásio mostra as mesmas microestruturas do estágio anterior e as biotitas sofrem intensa redução de tamanho de grão, ainda que mantendo os planos de clivagem paralelos à foliação principal.

$\mathrm{O}$ estágio de deformação de baixa temperatura foi caracterizado pelo intenso desenvolvimento de filonitos e milonitos que materializam as principais zonas de cisalhamento em ambos os granitóides. Por causa das temperaturas mais amenas, a deformação foi distintamente mais heterogénea, com a preservação de lentes onde as microestruturas dos estágios anteriores são comuns. O principal mecanismo de redução do tamanho do grão nesse estágio parece ser a nucleação de novos grãos, principalmente ao longo dos bordos do feldspato potássico, fraturas intragranulares e kinks dos plagioclásios. Um estágio ainda mais jovem de movimentação dessas zonas de cisalhamento, sob condições metamórficas de fácies xisto-verde e abundância de fluidos, foi reconhecido, sendo registrado por zonas discretas de milonitos, de espessura métrica, que retrabalharam os milonitos do estágio anterior. Essa última deformação é caracterizada por extensivo fraturamento e substituição de feldspatos por mica branca e biotíta, além de microestruturas sugestivas do predomínio de deslizamento basal em cristais de quartzo (Tommasi et al. 1994).

A sequência de rochas miloníticas originadas na ZCTDC mostra dobras contemporâneas às diversas fases de movimentação, restritas às faixas de orientação NE-SW, e que evidenciam a participação de uma componente de deformação coaxial associada ao fluxo não-coaxial dominante. Essas dobras sin-transcorrência são isoclinais, cilíndricas, com charneiras de orientação NE, paralelas às lineações de estiramento. Redobramentos coaxiais (padrão 'em laço') são frequentes, com as dobras mais jovens mostrando transposição ao longo da superfície axial e limbos, ao longo dos quais desenvolvem-se os milonitos de mais baixa temperatura. Essas estruturas mostram-se ainda afetadas por dobras tardias, mas ainda geneticamente relacionadas à movimentação das zonas de transcorrência, que atingiram também estruturas planares externas à ZCTDC. Desenvolvidas sob condições térmicas mais amenas (metamorfismo incipiente?), as dobras tardias são concêntricas, abertas a apertadas, com charneiras suborizontais de orientação NE e, caracteristicamente, mostram foliação plano-axial marcada por clivagens espaçadas.
Reativações das estruturas desse sistema de transcorrência, sob condições de temperaturas ainda mais baixas, formando rochas da série cataclástica, foram inúmeras durante o final do Pré-Cambriano e Fanerozóico. Isso foi evidenciado pelo controle dessas falhas na sedimentação (e.g. Fm Arroio dos Nobres, $c f$. Oliveira \& Fernandes 1991, 1992) e mesmo na preservação de sequências gonduânicas e mais jovens, cujos afloramentos, em escala regional, são restritos às zonas de filonitos com direção NE.

Assim, até que a obtenção de idades absolutas para as zonas de cisalhamento NE seja possível, propõe-se que a denominação "Dorsal de Canguçu" seja restrita às zonas de cisalhamento transcorrentes, originadas durante a evolução de um mesmo sistema termo-mecânico e que apresentem idades, história evolutiva e características estruturais e magmáticas compatíveis com aquelas descritas acima.

Sentido de movimentação das ZCTDC O sentido de movimentação relativa durante os diferentes estágios de ativação da ZCTDC foi determinado a partir do padrão apresentado pelas foliações e lineações magmáticas (estágio precoce e transicional) e estruturas deformacionais (estágios de deformação no estado sólido de alta e baixa temperatura).

Durante a fase de movimentação precoce ('estágio magmático'), os padrões de foliações e lineações magmáticas dos monzogranitos e granodioritos porfiríticos, evidenciados a partir da orientação dimensional de megacristais de feldspato potássico mostram direções variando entre NE e NS (estereogramas da Fig. 2a). Assumindo-se que a orientação dessas estruturas foi controlada pelo fluxo magmático, o qual, por sua vez, deve ter sido condicionado pela forma dos espaços disponíveis no campo tensional vigente, propõe-se uma forma de tension gash para as 'câmaras magmáticas' originadas durante esse período. Assumindose, ainda, natureza transtensional para as zonas de cisalhamento durante esse estágio de movimentação, devido a necessidade de criação de espaços para o posicionamento dos granitóides sintectônicos, pode-se deduzir movimento levógiro para essa fase de movimentação da ZCTDC, a partir do padrão apresentado pelas estruturas magmáticas observadas (Fig. 2a).

A movimentação levógira do estágio magmático estaria igualmente de acordo com a manutenção do mesmo campo tensional durante os estágios finais de movimentação das estruturas da ZCTDC. A determinação do sentido de movimentação relativa do evento de mais alta temperatura é dificultada tanto pela raridade dos registros dessa deformação em rochas mais antigas, quanto pela complexidade introduzida por abundantes estruturas mesoscópicas (principalmente dobras) parcialmente responsáveis pela determinação de sentidos de cisalhamento conflitantes (dextrógiro e levógiro) para essas estruturas nos granitóides deformados.

Destarte, o sentido de movimento relativo levógiro para as estruturas de mais baixa temperatura é bastante evidente, pelo menos na região de Encruzilhada do Sul (cf. Fernandes et al. 1990, UFRGS 1992, 1993). Essa última interpretação foi baseada não-apenas em indicadores cinemáticos, tais como sombras de pressão, assimetria de caudas de recristalização e fraturas intracristalinas de baixo e alto ângulo em feldspato, micafish e bandas de cisalhamento nos milonitos e filonitos; mas também, a partir da inflexão dos trenas de tectonitos com estruturas mais antigas (NE-E) e de temperatura mais alta, rotacionadas para o paralelismo com as zonas de cisalhamento tardias (NE-N).

A interpretação mais simples para o significado das deformações de mais alta temperatura (e mais penetrativa) e de mais baixa temperatura (e mais localizada) é a de que essas tenham se desenvolvido durante dois estágios de movimentação da ZCTDC, que correspondem a diferentes momentos da deformação progressiva (mesmo campo tensional), sob 

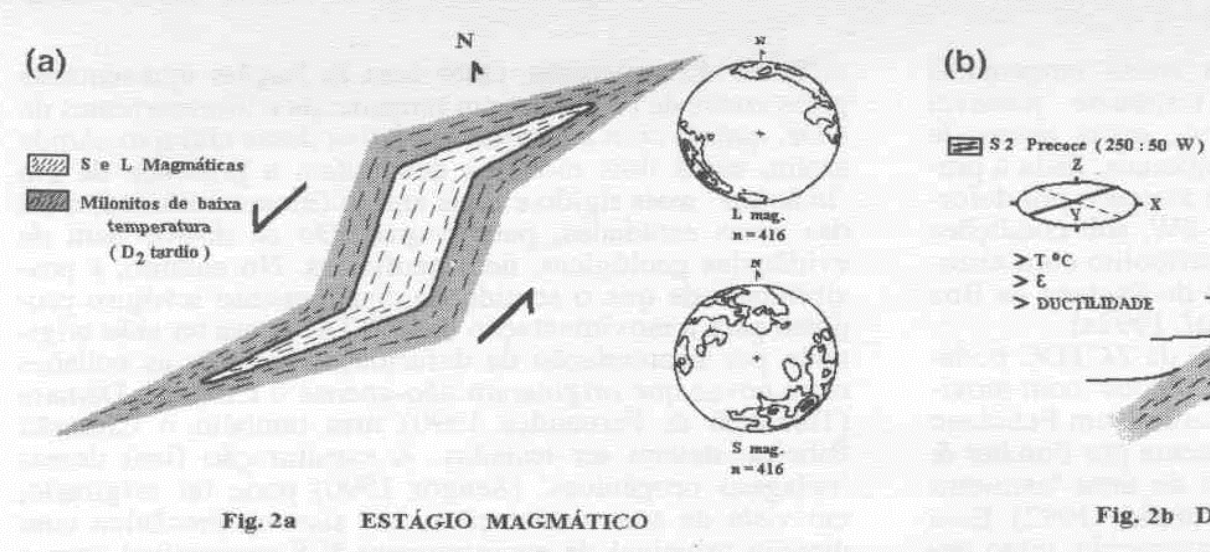

$\mathbf{N}$

P

(b)

Revista Brasileira de Geociências, Volume 23, 1993

Figura 2 - Movimento relativo sinistrai deduzido para os diferentes estágios de movimentação da Zona de Cisalhamento Transcorrente Dorsal de Canguçu (ZCTDC). a. Forma de tension gash inferida para os espaços de posicionamento dos monzogranitos e granodioritos porfiríticos sintectônicos à ZCTDC, a partir dos padrões de variação das estruturas magmáticas. Uma possível localização dessas estruturas no modelo tectônico regional é mostrada na figura $3 b$. b. Variação dos trends das estruturas da fase de deformação de mais alta temperatura (NE-E) para a de mais baixa temperatura (NE-N,) mantendo-se a mesma orientação da deformação geral

Figure 2 - Left-lateral sense of movement deduced for the different stages of movement of Dorsal de Canguçu Strike-Slip Shear Zone (DCSSZ). a. Shape of tension gash inferred for spaces of intrusion of porphyridc monzogranites and granodiorites syntectonic to DCSSZ from distribution pattern of magmatic structures. A possible localization of these structures in the regional tectonic model is shown in figure $3 \mathrm{~b}$. b. Variation of trends of high-temperature (NEE) to low-temperature (NE-N) structures keeping the same orientation of the bulk-strain

condições decrescentes de temperatura (metamorfismo retrogressivo). Durante a evolução da deformação, teria havido uma diminuição do ângulo 2 teta com a rotação das superfícies de cisalhamento acompanhada de localização progressiva da deformação entre os estágios de movimentação de mais alta e mais baixa temperatura (Fig. 2b). Desse modo, não haveria a necessidade de postular-se uma inversão do sentido de movimento entre o estágio magmático e o de deformação de baixa temperatura, deduzido e determinado como levógiros, respectivamente, para explicar os sentidos conflitantes observados nos tectonitos de temperatura mais alta. Muito menos, haveria a necessidade de proposição de modificações do campo tensional geral, considerada como ainda mais improvável, por causa da escala de atuação e natureza dos processos tectônicos que produzem essas deformações.

DISCUSSÃO FINAL Hipóteses de que a Zona de Cisalhamento Dorsal de Canguçu constitui-se numa sutura entre dois blocos crustais de origem e natureza marcadamente diferentes (Picada 1971, Issler 1982, Fragoso-César et al. 1986) podem ser descartadas com base tanto em suas características tectônicas e de magmatismo associado quanto por resultados de mapeamento litoestrutural de detalhe (UFRGS 1988, 1992, 1993), nos quais a inexistência de diferenças litológicas ou estruturais significativas entre unidades (associações petrotectônicas) mais antigas separadas por essas estruturas foi claramente demonstrada. De qualquer modo, se a ocorrência de granitóides porfiríticos apresentando feições idênticas àqueles posicionados sintectônicamente à fase de movimentação precoce do sistema Dorsal de Canguçu (como observado na região de Porto Alegre - RS), fosse considerada diagnostica da presença de outras estruturas de idade e características semelhantes às da ZCTDC, estaria-se corroborando a natureza intracontinental da mesma.

Igualmente, a interpretação de que a ZCTDC poderia representar "[...] uma sutura intraplaca, marcando a colisão do arco magmático do período anterior com as bacias do Grupo Porongos [...]" (Fragoso-César et al. 1986, p. 1333) não foi confirmada. Isso porque, essas zonas de cisalhamento seccionam metagranitóides do Complexo Arroio dos
Ratos contendo xenólitos de rochas supracrustais da Suíte Metamórfica Várzea do Capivarita (Fernandes et al. 1988,1990), que, segundo esses mesmos autores (FragosoCésar et al. 1982, 1986), representam, respectivamente, granitóides cordilheiranos e depósitos de margem continental passiva e bacia marginal do Cinturão Dom Feliciano. Assim, sugestões acerca da natureza de 'sutura colisionaP da ZCTDC foram possivelmente baseadas em fatores como a possança dessas estruturas e a presença de granitóides com duas micas. Esses últimos foram interpretados como granitos sincolisionais (cf. Fragoso-César et al. 1986, p. 1333), mais pelas suas semelhanças petrológicas gerais com os leucogranitos himalaianos do que pelas suas idades relativas e contexto tectônico. Por outro lado, as informações sobre as características de idades relativas, metamorfismo, deformação (geometria e cinemática) das rochas afetadas pela ZCTDC, bem como do magmatismo geneticamente associado, necessárias para suportar tal interpretação, são certamente incompatíveis com as mostradas por essas estruturas e rochas (cf. Fernandes et al. 1988, 1990, 1992a, 1992b, 1993, Tomrnasi 1991, Tommasi et al. 1993). Esses são, de fato, mais sugestivos de que a ZCTDC esteja associada a um evento de movimentação longitudinal no Cinturão Dom Feliciano, com características semelhantes aos que atualmente vem sendo reconhecidos em outros cinturões.

$\mathrm{O}$ reconhecimento da importância e magnitude de movimentos tectônicos paralelos ao alongamento de cinturões orogênicos é bastante recente, sendo os mesmos atribuídos a situações tectônicas diversas ( $c f$. Woodcock 1986, Sengor 1990, 1991, Vauchez \& Nicolas 1991). No caso do Cinturão Dom Feliciano no Escudo Sul-Rio-Grandense, a movimentação longitudinal parece ter sido acomodada principalmente pela ZCTDC e pelas zonas de alta deformação suborizontais (tangenciais) reconhecidas na Associação de Bacia Marginal (cf. Porcher \& Fernandes 1993). Tanto as zonas de alta deformação tangenciais, quanto as transcorrentes, apresentam histórias térmicas e deformacionais bastante semelhantes durante a movimentação tectônicalongitudinal, sendo caracterizadas por microestruturas e paragêneses de mais alta temperatura (fácies anfibolito) retrabalhadas sob condições de fácies xisto-verde. Mesmo com a ausência de dados radiométricos, os quais permiti- 
riam caracterizar inequivocamente as zonas tangenciais como sendo de idade brasiliana, tornou-se possível compatibilizar, numa primeira tentativa, essas zonas de cisalhamento em modelos tectônicos regionais, dada a presença de granitóides brasilianos e xistos afetados por deformação tangencial com movimento NE-SW, sob condições metamórficas retrogressivas da fácies anfibolito com xistoverde (Hartmann et al. 1990) na região de Santana da Boa Vista e Caçapava do Sul (Fernandes et al. 1992a).

Segundo esses modelos, as estruturas da ZCTDC poderiam corresponder a rampas laterais de 'blocos' com movimento paralelo ao alongamento do Cinturão Dom Feliciano (Fig. 3a), como especulado preliminarmente por Porcher \& Fernandes (1990), ou mesmo às raízes de uma 'estrutura em flor' (Fig. 3b), como sugerido por Porcher (1992). Essa última interpretação é presentemente favorecida, tanto pelas características petrológicas dos granitóides porfiríticos sintectônicos - sugestivas de sua origem mantélica - significando que essas zonas de cisalhamento atingiram pelo menos a base da crosta (Tommasi 1991, Tommasi et al. 1992a, 1994, Koester et al. 1993), quanto pela necessidade de compatibilizar o movimento de 'topo para NE' determinado na região de Santana da Boa Vista (Porcher 1992) e o sentido de cisalhamento sinistrai deduzido para a ZCTDC.

A posição geotectônica das ZCTDC, em relação à configuração geodinâmica responsável pela estruturação do Cinturão Dom Feliciano, não foi, ainda, inequivocamente determinada, pelas dificuldades envolvidas no estabelecimento de uma reconstrução dessa natureza, mesmo com a utilização de critérios não-puramente paleogeográficos (cf. Menegat \& Fernandes 1993). No entanto, é seguro afirmar que se tratam de zonas tardias em relação a evolução da subducção que originou os granitóides cordilheiranos da Associação de Arco Magmático I (Tommasi \& Fernandes 1990, Fernandes et al. 1992a, 1992b), visto que afetam os mesmos. Além disso, tendo-se em consideração a sua disposição e características gerais, não foi possível classificar as mesmas de acordo com as sistematizações existentes para ambientes tectônicos de falhas transcorrentes, como por exemplo, a proposta por Woodcock (1986, Fig. 6 e Table I). Dentre os modelos tectônicos conhecidos e capazes de acomodar movimentos longitudinais (cujas características principais foram sintetizadas na Tab. I), os de tectonic escape e 'instabilidade gravitacional' são os que apresentam as menores discrepâncias, tanto com as feições apresentadas pelas zonas de cisalhamento tangenciais e transcorrentes do CDF, quanto com a história evolutiva desse cinturão. Ainda assim, esses dois modelos demandam a presença de um 'indentor' mais rígido e mais antigo (bloco cratônico) a SE das áreas estudadas, para o qual não se dispõe nem de evidências geológicas, nem geofísicas. No entanto, a possibilidade de que o sentido de cisalhamento levógiro proposto para a movimentação da ZCTDC possa ter sido originado por acomodação da deformação durante as colisões mais novas que originaram não-apenas o Cinturão Damara (Tommasi \& Fernandes 1990) mas também o Cinturão Ribeira, devem ser testadas. A estruturacão final dessas 'colagens orogênicas' (Sengör 1990) pode ter originado, em vista de suas orientações, um sistema mecânico com direção principal de encurtamento N-S compatível com o campo tensional necessário para a movimentação sinistrai da ZCTDC (c/.Figs. 1 e 2b).

A hipótese de 'colisão oblíqua', como inicialmente especulada por Fragoso-César et al. (1986) e tradicionalmente adotada por autores subsequentes (em decorrência da magnitude e importância das zonas de transcorrência), pode ser descartada em virtude do padrão de deformação apresentado pêlos granitóides cordilheiranos da Associação de Arco Magmático I. Essas rochas mostram evidências de deformação precoce com transporte transversal ao alongamento do cinturão, indicando um alto ângulo de convergência entre as unidades mais antigas desse sistema geodinâmico - os Crátons Rio de La Plata e Kalahari (Tommasi et al. 1992b). $\mathrm{Na}$ estruturação de colagens orogênicas, eventos de acresção que apresentem vetores de convergência oblíqua, mesmo que apenas levemente diferentes de uma colisão frontal, mostram feições indicativas da ocorrência de deslocamentos paralelos ao Orógeno desde os estágios precoces da sua evolução ( $c f$. Tab. I), o que não parece ser o caso do Cinturão Dom Feliciano.

A correlação entre as ZCTDC e outras estruturas com situações e características similares, como as Zonas de Cisalhamento Major Gercino e Sierra Ballena, foi dificultada pela carência generalizada de informações, principalmente a respeito das características estruturais das mesmas.

As informações disponíveis sobre o magmatismo sintectônico à Zona de Cisalhamento Major Gercino (ZCMG), que separa os metassedimentos do Grupo Brusque dos grani-

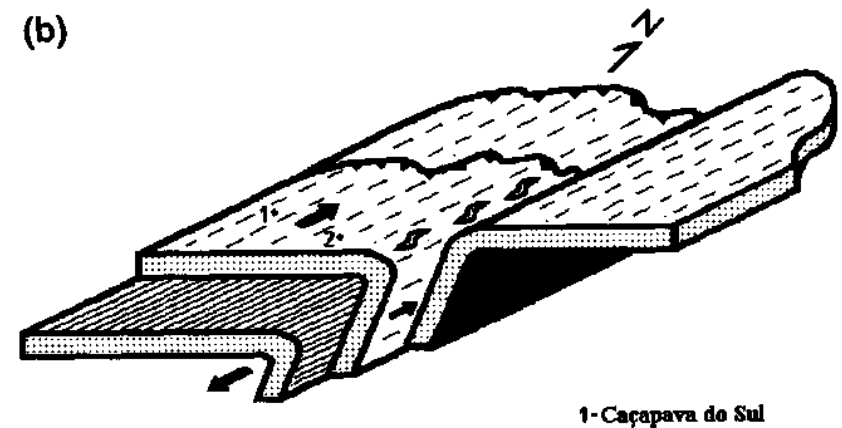

1-Caçapava do Sul

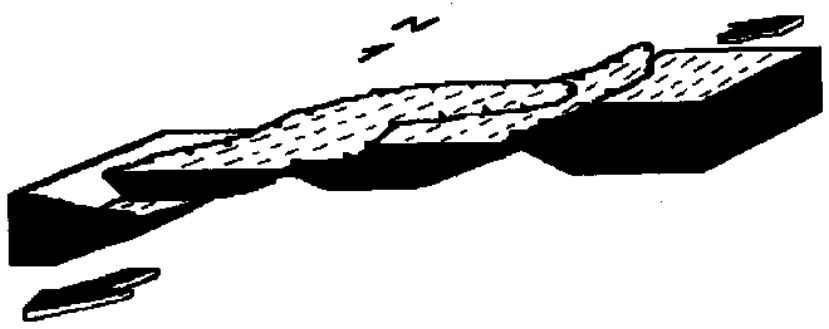

2- Sentana da Boa Vista

Figura 3 - Possíveis modelos tectônicos de compatibilização das zonas de cisalhamento transcorrentes 'Dorsal de Canguçu' e tangenciais da Bacia Marginal (região de Santana de Boa Vista-Caçapava). Diagramas hipotéticos ilustrando os modelos de (a) blocos com rampas laterais e flats (extraído de Porcher \& Fernandes 1990, Fig.12) e (b) de 'estrutura em flor' mostrando as tension gashes onde poderiam ter sido posicionados os granitóides porfiríticos (cf. Fig. $2 a$ ). O segundo modelo (b) é favorecido devido as características petrológicas e padrão das estruturas magmáticas dos granitóides porfiriticos sintranscorrência

Figure 3 - Possible tectonic models to make compatible the strike-slip Dorsal de Canguçu and flat-lying shear zones of the Marginal Basin Assemblage (Santana da Boa Vista-Caçapava region). Hypothetical diagrams showing models of (a) lateral ramps and flats (extracted from Porcher \& Fernandes 1990, Fig. 12) and (b) of flower-structure showing tension gashes where the syntranscurrent porphyritic granitoids could nave been emplaced (cf. Fig. 2a). The latter is favoured by the petrological characteristics and pattern of magmatic structures presented by the syntranscurrent granitoids 
Tabela 1 - Principais características dos modelos tectônicos capazes de acomodar deformação longitudinal em cinturões orogênicos

Table 1 - Main characteristics of the tectonic models capable of accommodating longitudinal deformation in orogenic beltos

\begin{tabular}{|c|c|c|c|c|c|}
\hline$\gamma^{\text {MODELOS }}$ & $\begin{array}{c}\text { SUBDUCCAO/COLISAOO } \\
\text { OBEAQUA }\end{array}$ & $\begin{array}{l}\text { TECTON/C } \\
\text { ESCAPE }\end{array}$ & $\begin{array}{l}\text { WSTABHLIDADE GRAVI- } \\
\text { TACIONAL: GERAÇAO } \\
\text { DE DESACOPLAMENTO } \\
\text { LATERAL }\end{array}$ & $\begin{array}{c}\text { ACRESÇĀo } \\
\text { TRANSCORRENTE }\end{array}$ & $\begin{array}{l}\text { ROTAÇĀo } \\
\text { DE BLOCO }\end{array}$ \\
\hline $\begin{array}{l}\text { GEOMETRIA } \\
\text { DAS ZONAS }\end{array}$ & $\begin{array}{l}\text { A zona principal mergulha } \\
\text { moderadamente para o conti- } \\
\text { nente. } \\
\text { As fallas subsidiarias podem } \\
\text { ser subverticais. }\end{array}$ & $\begin{array}{l}\text { Falhas subverticais. } \\
\text { Geometria variada de falhas } \\
\text { reativadas. }\end{array}$ & $\begin{array}{l}\text { Falhas normais de baixo in- } \\
\text { gulo } e \text { zonas horizontais de } \\
\text { desacoplartento. }\end{array}$ & $\begin{array}{l}\text { A zona de cisalbamento prin- } \\
\text { cipal e vertical. } \\
\text { Reativaf̧a de falhas antigas } \\
\text { com várias geomettias tos } \\
\text { blocas acrescionados. }\end{array}$ & $\begin{array}{l}\text { Principalmente zonas subver- } \\
\text { ticais, formadas a - } 90^{\circ} \text { do } \\
\text { vetor de convergencia. } \\
\text { Padråo em arco frequen- } \\
\text { temente observado (conti- } \\
\text { nental). }\end{array}$ \\
\hline CINEMATJCA & $\begin{array}{l}\text { Todas as zonas tem o mesmo } \\
\text { sentido de movimentaçlo. } \\
\text { o fluxo na zona principal e } \\
\text { obliquo od ocomem mov. nor- } \\
\text { mal e paralelo ao cinturato. }\end{array}$ & $\begin{array}{l}\text { Zomas de falha nos limites dos } \\
\text { blocos expulsos mostram sen- } \\
\text { tido de deslocamento oposto. } \\
\text { Blocos expulsos afastam-se } \\
\text { do indentor. }\end{array}$ & $\begin{array}{l}\text { A placa superior afasta-se do } \\
\text { indentor. Deslocamentos dj- } \\
\text { vergentes podem ser regis- } \\
\text { trados nos dois lados do } \\
\text { indentor. }\end{array}$ & $\begin{array}{l}\text { Todas as zonas de cisalha- } \\
\text { mento apresentam o mesmo } \\
\text { sentido de movimento parale- } \\
\text { lo a zona de sutura. }\end{array}$ & $\begin{array}{l}\text { Zonas de falha tém o memo } \\
\text { sentido de cis. no mesno lado } \\
\text { do indentor e sentido oposto } \\
\text { em lados contrários. Rotaça } \\
\text { dos bls. diferente em cada } \\
\text { lado. }\end{array}$ \\
\hline $\begin{array}{l}\text { OCORRENCIA DE } \\
\text { DESLOCAMENTOS } \\
\text { PARALELOS AO } \\
\text { CINTURAO DURANTE } \\
\text { OS PROCESSOS } \\
\text { TECTONICOS }\end{array}$ & $\begin{array}{l}\text { Precoce, ainda anies da coli- } \\
\text { șo. }\end{array}$ & $\begin{array}{l}\text { Tardia, subsequidente acres- } \\
\text { ça. }\end{array}$ & $\begin{array}{l}\text { Tardia, subsequiente à colisła } \\
\text { e espessamento crustal. }\end{array}$ & $\begin{array}{l}\text { No comego do processo de } \\
\text { acresçțo. } \\
\text { Algumas vezes mesmo antes } \\
\text { dos terrenos estarem em con- } \\
\text { tato. }\end{array}$ & $\begin{array}{l}\text { Tardia, subsequente a acres- } \\
\text { ção. Necessita que uma gran- } \\
\text { de deformaçđ̃o do bloco em- } \\
\text { purrado seja completada. } \\
\text { Deformação intracontinental } \\
\text { tf́pica. }\end{array}$ \\
\hline $\begin{array}{l}\text { ENCURTAMENTO } \\
\text { TRANSVERSAL } \\
\text { ESPESSAMENTO } \\
\text { CRUSTAL E } \\
\text { SOERGUIMENTO }\end{array}$ & $\begin{array}{l}\text { Encurtamento simultaneo do } \\
\text { desloc, transcorrente. } \\
\text { Espessam. crustal e soer- } \\
\text { guimento variável dependen- } \\
\text { do do fungulo de convergéncia. }\end{array}$ & 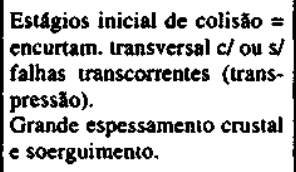 & $\begin{array}{l}\text { Estagios inicizis de colisajo = } \\
\text { eneurtam. transversal c/ ou } s / \\
\text { falhas transcorrentes (trans- } \\
\text { pressäo). } \\
\text { Grande espessamento crustal } \\
\text { e soerguimento. }\end{array}$ & $\begin{array}{l}\text { Nenhum (ou limitado) ençur- } \\
\text { tamento transversal. } \\
\text { Nenbum (ou limitado) espes- } \\
\text { samento crustal e soer- } \\
\text { guimento. }\end{array}$ & $\begin{array}{l}\text { Estágios precoces da oroge. } \\
\text { nese = colista continental } \\
\text { causando encurtamento espes- } \\
\text { samento crustal e soer- } \\
\text { guimento. }\end{array}$ \\
\hline $\begin{array}{l}\text { METAMORFTSMO E } \\
\text { ANOMALIA TERMAL }\end{array}$ & $\begin{array}{l}\text { Metamorfisimo de AP simul- } \\
\text { tâneo of mov, transcorrente } \\
\text { na zona de colisäo. } \\
\text { Pico de anomalia termal an- } \\
\text { tecede os mov. paral. preco- } \\
\text { ces. }\end{array}$ & $\begin{array}{l}\text { Metamorfismode AP anterior } \\
\text { ao movim. transc. e simultá- } \\
\text { neo cavalgamento precoce } \mathrm{Pj}- \\
\text { co de anomalia termica ante- } \\
\text { rior a trantscorrencia. }\end{array}$ & $\begin{array}{l}\text { Metamorfismo de AP ante- } \\
\text { tior a transcor. e simultầneo } \\
\text { cavalg. precoce. } \\
\text { Pico de anom. térm. anterior } \\
\text { a transcorrénciz. }\end{array}$ & $\begin{array}{l}\text { Sem metamorfismo de AP. } \\
\text { Desenvolvimento de anoma- } \\
\text { fja térmica simulttinea ao mo- } \\
\text { vimento longitudinal. }\end{array}$ & $\begin{array}{l}\text { Metamorfismo de AP anterior } \\
\text { a transe. e simultåneo ao ca- } \\
\text { valgamento precoce. } \\
\text { Pico de anomalia térmica an- } \\
\text { terior ou simultâneo à trans- } \\
\text { corréncia }\end{array}$ \\
\hline $\begin{array}{l}\text { DEFORMAÇĀO DO } \\
\text { MANTO SUPERIOR E } \\
\text { ANISOTROPIA SISMICA }\end{array}$ & $\begin{array}{l}\text { Manto sup. e crosta com a } \\
\text { mesma def. no estágio inicial. } \\
\text { Anisotropia sismica: direçăo } \\
\text { de maior velocidade }\end{array}$ & $\begin{array}{l}\text { Fluxo normal th zona de sutu- } \\
\text { Ja na colisło. Retrabuthaut. do } \\
\text { manto sup. por zomas litosft- } \\
\text { ricas paralelas ao cinturão. } \\
\text { Anis. sísm. complexa. }\end{array}$ & $\begin{array}{l}\text { Sem def. associada do manto } \\
\text { superior. } \\
\text { O manto sup. pode manter re- } \\
\text { gistro da dir. fluxo precoce } \\
\text { (nomal a zona de sutura). }\end{array}$ & $\begin{array}{l}\text { Manto sup. deformado da } \\
\text { mesma forma que a crosta (a } \\
\text { z. principal de mov. é uma } \\
\text { falba litosferica). Maior vel. } \\
\text { paralela 2. sutura (anis. sism.) }\end{array}$ & $\begin{array}{l}\text { Fluxo no manto sup- princi- } \\
\text { paltuente paralelo a vetor } \\
\text { de convergencia. Anisotropia } \\
\text { sísmica devida a convergên- } \\
\text { cia nilo e modificada pela } \\
\text { transcorrencia }\end{array}$ \\
\hline
\end{tabular}

$\mathrm{AP}=$ alta pressão

tóides do 'domínio interno' (Basei \& Hawkesworth 1993, Bitencourt et al. 1993), parecem indicar tratarem-se de rochas graníticas mais novas e mais diferenciadas, como inferido a partir de suas idades e características geoquímicas, em relação à evolução magmática dos granitóides do Cinturão Dom Feliciano (cf. Fernandes et al. 1992b). Embora as temperaturas estimadas (a partir das microestruturas?) para a deformação na ZCMG e seu contexto geológico sejam compatíveis com as da ZCTDC, os sentidos de cisalhamento, reportados como dextral (Bitencourt et al. 1989) e 'predominantemente dextral' (Passarelli et al. 1993), são incompatíveis com a interpretação apresentada nesta contribuição, evidenciando a necessidade de esclarecimento dessa questão.

As microestruturas dos tectonitos e o contexto geológico da Zona de Cisalhamento Sierra Ballena (ZCSB) parecem indicar tratar-se a mesma de estrutura formada sob condições de baixa temperatura. No contexto tectônico evolutivo do Cinturão Dom Feliciano, essa zona de cisalhamento seria uma estrutura mais jovem $e$, portanto, equivalente às zonas de baixa temperatura dos estágio finais de movimentação da ZCTDC, interpretação essa que estaria de acordo com as idades mínimas de $535 \pm 15$ Ma estimadas para a movimentação da ZCSB no Uruguai (Bossi \& Campal 1992).
No Escudo Sul-Rio-Grandense, essas idades correspondem à intrusão dos feldspato potássico e pertita granitos que não apresentam evidências de terem sofrido deformação dúctil.

A magnitude de deslocamento total estimada para a ZCTDC deve ser modesta, tanto pela similaridade entre unidades litoestratigráficas aflorantes em ambos os lados da zona de cisalhamento (granitóides cordilheiranos da Associação de Arco Magmático I com xenólitos das rochas supracrustais da Suíte Metamórfica Várzea do Capivarita, cf. Fernandes et al. 1992b), quanto a partir de considerações teóricas baseadas na extensão da ZCTDC (cf. Cowie $\&$ Scholz 1992, Fig. 3b), apesar de deslocamentos da ordem de poucas centenas a milhares de quilómetros terem sido verificadas para zonas de cisalhamento litosféricas com direção paralela a colagem orogênica (cf. Vauchez \& Nicolas 1991). No entanto, a ocorrência de grandes rejeitos ao longo da ZCTDC não pode ser descartada apenas com base nas poucas evidências disponíveis até o momento. Com efeito, há a possibilidade de que o movimento principal tenha sido paralelo ao alongamento da Associação de Arco Magmático I e, nesse caso, ficaria mantida portanto, uma mesma associação de rochas em ambos os lados da zona de cisalhamento, como ocorre de fato na ZCTDC. 
Mais recentemente, algumas das estruturas da ZCTDC têm sido interpretadas como limites entre 'terrenos'. No entanto, parece evidente a partir do exemplo discutido que, independentemente dos conceitos de 'tectónica de terrenos' serem ou não os mais apropriados para o estabelecimento da compartimentação tectônica do Pré-Cambriano no Escudo Uruguaio-Sul-Rio-Grandense (cf. Sengör \& Dewey 1990, Sengör 1991), o estudo das zonas de cisalhamento propostas como limite para os mesmos deve ser direcionado no sentido de demonstrar o papel dessas feições na estruturação da colagem orogênica. Esse objetivo, no entanto, só pode ser atingido através da caracterização, o mais detalhada possível, do contexto geológico regional, magmatismo associado e evolução estrutural das zonas de cisalhamento, com o intuito de restringir ao máximo a vasta gama de possibilidades teóricas acerca da natureza e história evolutiva dessas estruturas, independentemente dos modelos tectônicos propostos para a estruturação do Cinturão Dom Feliciano.

Agradecimentos Agradecemos aos colegas J.C. Frantz, M.F.A.S. Bitencourt, M.C.P. Gastai, do IG-UFRGS, e aos académicos dos Trabalhos de Graduação na Região de Encruzilhada do Sul (formandos das turmas de 1988,1992 e 1993) pelas discussões de campo, e aos bolsistas André Bastos e Karem Costa pelo auxílio com a arte final das ilustrações. O trabalho foi possível graças ao apoio do $\mathrm{CNPq}$, sob a forma de bolsa de pesquisa.

\section{REFERÊNCIAS BIBLIOGRÁFICAS}

AGUE, J.J. \& BRIMHALL, G.H. 1988. Magmatic are asymmetry and distríbution of anomalous plutonic belts in the batholiths of Califórnia: Effects of assimilation, crustal thickness, and depth of crystallization. Geol. Soe. Am. Buli., 100:912-927.

BASEI, M.A.S. \& HAWKESWORTH, C. 1993. O magmatismo do Cinturão Dom Feliciano (SC) e sua importância no estabelecimento das principais descontinuidades crustais da região Sul-brassileira. In: SIMP. INTERN. DEL NEOPROTEROZOICO-CAMERICO DE LA CUENCA DEL PLATA, 1. Lãs Palomas-Minas, 1993. Boletim de Resumos Expandidos.... Lãs Palomas-Minas, Uruguay, DI.NA.MI.GE. Tomo 2, resumo $n^{9} 41$

BITTENCOURT, M.F.A.; HACKSPACHER, P.C.; NARDI, L.V.S. 1989. A Zona de Cisalhamento Major Gercino-Santa Catarina. In: SIMP. NAC. EST. TECT., 2. Natal, 1989. Boletim de Resumos... Natal, SBG. p. 214-216.

BITTENCOURT, M.F.; NARDI, L.V.S.; HACKSPACHER, P.C. 1993. Evolução do magmatismo brasiliano na Zona de Cisalhamento Major Gercino. In: SIMP. INTERN. DEL NEOPROTEROZÓICOCAMBRICO DE LA CUENCA DEL PLATA, 1. Lãs Palomas-Minas, 1993. Boletim de Resumos Expandidos... Lãs Palomas-Minas, Uruguay, DI.NA.MI.GE. Tomo 2, resumo $\mathrm{n}^{9} 33$.

BELOUSSOV, V.V. 1962. Basic Problems in Geotectonics. New York, McGraw Hill. $816 \mathrm{p}$.

BOSSI, J. \& CAMPAL N. 1992. Magmatismo y tectônica transcurrente durante el Paleozóico Inferior en Uruguay. In: MARCO, J.G.G.; SAAVEDRA, J.; RÁBANO, I. eds. Actas dei Simpósio Internacional sobre o Paleozóico Inferior de Latinoamérica. Salamanca, Universidad Extremadura. p. 343-356.

CARRARO, C.C.; GAMERMANN, N.; EICK, N.C.; BORTOLUZZI, C.A.; JOST, H.; PINTO, J.F. 1974. Mapa Geológico do Estado do Rio Grande do Sul. Porto Alegre, UFRGS. (Pesquisas - Série Mapas).

CARVALHO, P.F. 1932. Reconhecimento geológico do Rio Grande do Sul. Boi. IGMB, 66:1-72

COWIE, P.A. \& SCHOLZ, C.H. 1992. Displacement-length scaling relationship for faults: data synthesis and discussion. J. Struct. Geol., 14:1149-1156.

FERNANDES, L.A.D.; TOMMASI, A.; PORCHER, C.C.; MARQUESTOIGO, M.; GUERRA-SOMMER, M.; PICCOLI, A.E.M. 1988. Mapa Geológico de Parte das Folhas de Quitéría e Várzea do Capivarita - RS. Porto Alegre, UFRGS. (Pesquisas - Série Mapas).

FERNANDES, L.A.D.; TOMMASI, A.; PORCHER, C.C. 1990. Esboço estrutural de parte do Batólito Pelotas - região de Quitéria-Capivarita. Acta Geol. Leopold., 13:117-138.

FERNANDES, L.A.D.; TOMMASI, A.; PORCHER, C.C.; MENEGAT, R. 1991. Correlação estrutural cinemática em faixas móveis: Uma discussão. In: SIMP. NAC. EST. TECT., 3. Rio Claro, 1991. Boletim de Resumos... Rio Claro, SBG. p. 166-168.

FERNANDES, L.A.D.; TOMMASI, A.; PORCHER, C.C. 1992a. Deformation Patterns in the southern brazilian branch of the Dom Feliciano Belt: A reappraisal. J. South Am. Earth Sei., 5:77-96.

FERNANDES, L.A.D.; TOMMASI, A. ; PORCHER, C.C.; KOESTER, E.; KRAEMER, G.; SCHERER, C.M.S.; MENEGAT, R. 1992b. Granitóides brasilianos precoces do Cinturão Dom Feliciano. Caracterização geoquímica e discussão estratigráfica. Pesquisas, 19:197218.

FERNANDES, L.A.D.; TOMMASI, A.; PORCHER, C.C.; VAUCHEZ, A. 1993. Zonas de Cisalhamento Transcorrentes do Cinturão Dom Feliciano; Caracterização e importância tectônica. In: SIMP. INTERN. DEL NEOPROTEROZÓICO-CAMBRICO DE LA CUENCA DEL PLATA, 1. Lãs Palomas-Minas, 1993. Boletim de Resumos Expandidos... Lãs Palomas-Minas, Uruguay, DI.NA.MI.GE. Tomo 1, resumo $\mathrm{n}^{\mathrm{s}} 19$.

FIGUEIREDO, M.C.H.; FRAGOSO-CÉSAR, A.R.S.; KRONBERG, B.I. 1990. Litogeoquímica das principais unidades do Batólito Pelotas no Rio Grande do Sul. In: CONGR. BRÁS. GEOL., 36. Natal, 1990. Anais... Natal, SBG. v. 6, p. 1723-1738.
FRAGOSO-CÉSAR, A.R.S; WERNICK, E. SOLIANI Jr, E. 1982. Evolução geotectônica do Cinturão Dom Feliciano - uma contribuição através da aplicação do modelo de Tectônica de Placas. In: CONGR. BRÁS. GEOL., 32. Salvador, 1982. Anais... Salvador, SBG. v. 1, p. 13-23.

FRAGOSO-CËSAR, A.R.S.; FIGUEIREDO, M.C.H.; SOLIANI Jr., E.; FACCINI, U.F. 1986. O Batólito Pelotas (Proterozóico Superior/ Eo-Paleozóico) no Escudo do Rio Grande do Sul. In: CONGR. BRÁS. GEOL., 34. Goiânia, 1986. Anais... Goiânia, SBG. v. 3, p. $1322-1342$.

FRAGOSO-CÉSAR, A.R.S; MACHADO, R.; MONTEIRO, R.L.; SALLET, R. 1990. Nappes e estruturas correlatas do Cinturão Dom Feliciano no Escudo Uruguaio-Sul-Rio-Grandense: Uma introdução ao problema. Acta Geol. Leopold., 30:75-93.

FRANTZ, JC. \& JOST, H. 1983. Petrologia dos granitos estaníferos do Rio Grande do Sul. In: SIMP. SUL-BRAS. GEOL., 1. Porto Alegre, 1983. Anais... Porto Alegre, SBG. p. 49-67.

HARTMANN, L.A.; TINDLE, A.; BITENCOURT, M.F. 1990. O metamorfismo de fácies anfibolito no Complexo Passo Feio, RS, com base em química dos minerais. Pesquisas, 17:62-71.

ISSLER, R.S. 1987. Granitos e granitóides da região sul. Pesquisas, 20:125-184.

JOST, H. 1981. Geology and Metallogeny of the Santana da Boa Vista Region, Southern Brazil- Georgia. 208 p. (PhD Thesis, University of Georgia).

JOST, H.; FRANTZ, J.C.; BROD, J.A. 1984. Revisão da tipologia, cronologia e significado geotectônico dos falhamentos do Escudo Sul-RioGrandense. In: CONGR. BRÁS. GEOL., 33. Rio de Janeiro, 1984. Anais... Rio de Janeiro, SBG. v. 3, p. 1707-1720.

KIRBY, S.H. 1985. Rock mechanics observations pertinent to the rheology of the continental lithosphere and the localization of strain along shear zones. Tectonophysics, 119:1-27.

KNIPE, RJ. 1989. Deformations mechanisms - recognition from natural tectonites. /. Struct. Geol, 11:127-146.

KOESTER, E. 1995 Petrologia e geocronologia dos granitóides sintectônicos à Zona de Cisalhamento Dorsal de Canguçu. Porto Alegre. 240 p. (Dissertação de Mestrado, CPG/UFRGS).

KOESTER, E.; FERNANDES, L.A.D.; KRAEMER, G. 1993. Geologia dos granitóides sincinemáticos à Zona de Cisalhamento Dorsal de Canguçu. In: SIMP. INTERN. DEL NEOPROTEROZÓICOCAMBRICO DE LA CUENCA DEL PLATA, 1. Lãs Palomas-Minas, 1993. Boletim de Resumos Expandidos... Lãs Palomas-Minas, Uruguay, DI.NA.MI.GE. Tomo 2, resumo n 37.

LEINZ, V \& BARBOSA, A.F. 1941. A jazida de cobre "Cerro dos Martins". Mineração e Metalurgia, 5(30):252-8.

MELCHER, G. \& MAU, H. 1960. Novas observações geológicas na região de Caçapava do Sul, Rio Grande do Sul. An. Acad. bras. Ci., 32(1):43-50

MENEGAT, R. 1992. Das Minas de Cobre e Carvão ao Modelo de Colisão Continental. Contribuição ao Estudo da Mutação Epistemológica dos Modelos do Pré-Cambriano do Escudo Sul-Rio-Grandense (1823 a 1990). Porto Alegre. 308 p. (Dissertação de Mestrado, CPG/ UFRGS).

MENEGAT, R. \& FERNANDES, L.A.D. 1993. Critérios paleogeográfícos e cinemáticos no estabelecimento de modelos plaquistas para o Pré-Cambriano do Escudo Sul-Rio-Grandense: Uma abordagem epistêmica dos paradigmas. In: SIMP. INTERN. DEL NEOPROTEROZÓICO-CAMBRICO DE LA CUENCA DEL PLATA, 1. Lãs Palomas-Minas, 1993. Boletim de Resumos Expandidos... Lã̃s Palomas-Minas, Uruguay, DI.NA.MI.GE. Tomo 2, resumo $n^{9} 5$.

MESQUITA, M.J.M. \& FERNANDES, L.A.D. 1990. Petrografia dos granitóides deformados na Zona de Cisalhamento Dorsal de Canguçu (Região de Quitéria-Capivarita). Acta Geol. Leopold., 30:55-74.

NICOLAS A. \& POIRIER, J.P. 1976. Cristaline Plasticiy and Solid State Flow in Metamorphic Rocks. New York, Wiley \& Sons. 444 p. 
OLIVEIRA, J.M.M.T. \& FERNANDES, L.A.D. 1991. Estágios finais da evolução do Cinturão Dom Feliciano: tectônica e sedimentação da Formação Arroio dos Nobres. In: SIMP. NAC. EST. TECT., 3. Rio Claro, 1991. Boletim de Resumos.... Rio Claro, SBG. p. 58-59.

OLIVEIRA, J.M.M.T. \& FERNANDES, L.A.D. 1992. Bacias molássicas brasilianas: mito ou realidade? In: WORKSHOP SOBRE AS BACIAS MOLÁSSICAS BRASILIANAS, 1. Boletim Especial... São Leopoldo, UNISINOS, p. 97-105.

PASSARELLI, C.R.; BASEI, M.A.S.; CAMPOS NETO, M.C. 1993. Caracterização geométrica e cinemática da Zona de Cisalhamento Major Gercino e sua importância na compartimentacão dos terrenos pré-Cambrianos de Santa Catarina. In: SIMP. INTERN. DEL NEOPROTEROZÓICO-CAMBRICO DE LA CUENCA DEL PLATA, 1. Lãs Palomas-Minas, 1993. Boletim de Resumos Expandidos... Lãs Palomas-Minas, Uruguay, DI.NA.MI.GE. Tomo 1, resumo $\mathrm{n}^{\mathrm{e}} 23$.

PATERSON, 1987. Problems in the extrapolation of laboratory rheological data. Tecionophysics, 133:33-43.

PICADA, R.S. 1971. Ensaio sobre a tectônica do Escudo Sul-Riograndense. Caracterização dos sistemas de falhas. In: GONGR. BRÁS. GEOL., 25. Porto Alegre, 1971. Anais... Porto Alegre, SBG. p. 167-191.

POPPER, K. 1980. The Logic of Scientific Discovery. London, Hutchinson. 480 p.

PORCHER C.C. 1992. Caracterização das Condiç̃es de Fluxo em uma Zona de Cisalhamento Tangencial na Região de Santana da Boa Vista (RS). Porto Alegre. 192 p. (Dissertação de Mestrado, CPG-UFRGS).

PORCHER, C.C. \& FERNANDES, L.A.D. 1990. Relações embasamento/ "cobertura" na porção ocidental do Cinturão Dom Feliciano: um esboco estrutural. Pesquisas, 17:72-84.

PORCHER, C.C. \& FERNANDES, L.A.D. 1993. Evidências de uma zona de Cisalhamento com transporte longitudinal na Associação de Bacia Marginal do Cinturão Dom Feliciano no Rio Grande do Sul - Brasil. In: SIMP. INTERN. DEL NEOPROTEROZÓICO-CAMBRICO DE LA CUENCA DEL PLATA, 1. Lãs Palomas-Minas, 1993. Boletim de Resumos Expandidos DI.NA.MI.GE. Tomo 1 , resumo n 24.

RIBEIRO, M. 1980. Geossuturas do Escudo Sul-Riograndense. In: CONGR. BRÁS. GEOL., 31. Camboriú, 1980. Anais.... Camboriú, SBG. v. 5, p. $2709-2718$

RUTTER, E. \& BRODIE, K.H. 1991. Lithosphere rheology - a note of caution. /. Struct. Geol, 13(3):363-367.

SCHMID, S.M. 1982. Microfabric Studies as Indicators of Deformation Mechanisms and Flow Laws Operative in Mountain Building. In: HSÜ, KJ. ed. Mountain Building Processes. London, Academic Press. p. 95-111.

SENGÖR, A.M.C. 1990. Plate tectonics and orogenic research after 25 years: synopsis of a Tethyan perspective. Earth-Sci. Rev., 27:1-201.

SENGÖR, A.M.C. 1991. Plate tectonics and orogenic research after 25 years: synopsis of a Tethyan perspective. Tectonophysics, 187:315-344.

SENGÖR, A.M.C. \& DEWEY, J.F. 1990. Terranology: Vice or Virtue? Phil. Trans. R. Soe. London, 331(A):1-21.
TAPONNIER, P. \& MOLNAR, P. 1976. Slip-line field theory and large scale continental tectonics. Nature, 264:319-324.

TEIXEIRA, E.A. 1937. Tungsténio no Rio Grande do Sul. Mineração e Metalurgia, 2(4):255-257.

TESSARI, R.I. \& PICADA, R.S. 1966. Geologia da Quadrícula de Encruzilhada do Sul. Boletim da Divisão de Fomento da Produção Mineral. DNPM, 124:1-147.

TOMMASI, A. 1991. Evolução Cinemática do Cinturão Dom Feliciano Durante o Ciclo Brasiliano. Porto Alegre. 207 p. (Dissertação de Mestrado, CPGG-IG/UFRGS).

TOMMASI, A \& FERNANDES, L A.D 1990. O Ciclo Brasiliano na porção Sudeste da Plataforma Sul-Americana: Um novo modelo. In: CONGR. URUG. GEOL., 1. Montevideo, 1990. Boletim de Resumenes Ampliados... Montevideo, Sociedad Uruguaya de Geologia, v. 1, p. 107-114.

TOMMASI, A; FERNANDES, L.A.D; PORCHER, C.C.; VAUCHEZ, A 1992a. Magmatismo sincinemático em zonas de Cisalhamento litosféricas: origem e consequências reológicas. In: CONGR. BRÁS. GEOL., 37. São Paulo, 1992. Boletim de Resumos Expandidos... São Paulo, SBG. v. 2, p. 367-368.

TOMMASI, A.; FERNANDES, L.A.D; PORCHER C.C.; VAUCHEZ, A 1992b. Movimentação paralela e transversal aos limites de placas durante uma colisão continental - exemplo do Cinturão Dom Feliciano, RS. In: CONGR. BRÁS. GEOL., 37. São Paulo, 1992. Boletim de Resumos Expandidos... São Paulo, SBG. v. 2, p. 352-353.

TOMMASI, A.; VAUCHEZ, A.; FERNANDES, L.A.D.; PORCHER, C.C. 1994. Orogen-parallel strike-slip fauíting and synkinematic magmatism in the Dom Feliciano Belt of Southern Brazil. Tectonics, 13(2):421-437.

UFRGS 1988. Mapeamento Geológico de Parte das Folhas de Quitéria e Várzea do Capivarita. In: Trabalho de Graduação do Curso de Geologia. Porto Alegre, IG-UFRGS. (Inédito).

UFRGS 1992. Mapeamento Geológico de Parte das Folhas de Encruzilhada do Sul e Delfino. In: Trabalho de Graduação do Curso de Geologia. Porto Alegre, IG-UFRGS. (Inédito)

UFRGS 1993. Mapeamento Geológico de Parte das Folhas de Cerro da Arvore, Encruzilhada do Sul, Figueiras e Vau dos Prestes. In: Trabalho de Graduação do Curso de Geologia. Porto Alegre, IG-UFRGS. (Inédito).

VAUCHEZ, A. \& NICOLAS, A. 1991. Mountain building: strike-parallel motion and mantle anisotropy. Tectonophysics, 185:183-201.

VAUCHEZ, A. 1987. Mecanismes de Deformation et Cinematique dês Zones de Mouvement Ductile. France. 315 p. (Doctorat de Etat, Faculte de Sciences et Techniques de St. Jérome).

WOODCOCK, N. 1986. The role of strike-slip fault sistems at plate boundaries. Phil. Trans. R. Soe. London, 317:13-29.

MANUSCRITO A780

Recebido em 31 de agosto de 1993 Revisã 0 do autor em 7 de fevereiro de 1994 Revisã o aceita em 11 de fevereiro de 1994 